\title{
Floyd's Modified Computational Method Applied to Calculate Step Response of a Regilator from Frequency Response
}

\author{
Jose Flavio Feiteira, Jose Luiz Guarino, Rodrigo Guerra de Souza \\ Computational Modeling in Science and Technology, Universidade Federal Fluminense, Volta Redonda, Brazil
}

\section{Email address:}

galloguarino@gmail.com (J. L. Guarino),rodrigomcct@gmail.com (R. G. de Souza)

\section{To cite this article:}

José Flávio Feiteira, José Luiz Guarino, Rodrigo Guerra de Souza. Floyd's Modified Computational Method Applied to Calculate Step Response of a Regilator from Frequency Response. Science Journal of Circuits, Systems and Signal Processing. Vol. 8, No. 2, 2019 , pp. 47-52. doi: $10.11648 /$ j.cssp.20190802.13

Received: July 10, 2019; Accepted: August 12, 2019; Published: August 23, 2019

\begin{abstract}
This work explains how to obtain the unit step time domain response by means of the frequency response of a regulator (gain and phase) using the Floyd's Modified Computational Method. The preliminary condition is that the gain of the system tends to zero as the frequency tends to infinite. Floyd's Method uses the Fourier's Inverse Transform to achieve the Impulse Unit response. The Modified Method calculates the integral. This work details the mathematical developnent of Floyd's Method. Authors introduce the integral of the Impulse Unit response to obtain the Step Unit response and also the linearization of the Method in order to approximate it and obtain an equation to do the computational calculation. We apply the modified method in a second order system, calculating its frequency response and its analytic step unit response by means of the MNatlab. Then we use the equation developed in this work by the linearization of Floyd's Modified Method applied in the frequency response of the system and compare with the step unit analytic response. The relative error is calculated and we can observe that Floyd's Modified Method generates a step unit response in the time domain that has some time little retard and with values a little inferior to the analytic response. This behavior is attributed to the linearization and to do not use the complete frequency band of the system. However the final values are very exact. T.
\end{abstract}

Keywords: Floyd's Method, Impulse Unit Response, Step Unit Response, Frequency Domain, Time Domain, Fourier's Inverse Transform

\section{Introduction}

Figure 1 below shows a canonical form of a regulator, where $\mathrm{X}(\mathrm{s})$ is the reference, input, and the output is $\mathrm{Y}(\mathrm{s})$, which we desire to control.

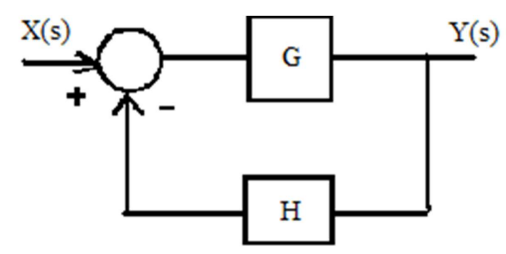

Figure 1. Canonical System.

Normally, there is no direct relation between the frequency response and the step unit response of regulators. As a rule of thumb we inject a $10 \%$ of the step input in the biased nominal input to determine the fulfillment of the system and to avoid saturations. [3-8]

This work, has the principle that having the response of the regulator in the frequency domain we wish to obtain the step unit response in the time domain i.e. the Floyd Method

Another objective of this work is to realize the Floyd's Modified Method with the Matlab.

We demonstrate the method mathematically, applying it to a second order system and analyze the errors. However this method is restrict to a regulator with closed loop gain $G(w)$ following the equation below, where $\mathrm{w}$ is the frequency in $\mathrm{rad} / \mathrm{s}$ :

$$
\lim _{w \rightarrow \infty} G(w)=0
$$




\section{Mathematical Discussion}

\subsection{Impulse Unit Response [2, 10-12]}

Fourier's Inverse Transform is:

$$
f(t)=\frac{1}{2 \pi} \int_{-\infty}^{\infty} F(w) e^{j w t} d w
$$

Supposing an impulse unit step $\delta(t)$ to the system $\mathrm{G}$, as shown in figure 2, the Fourier's Transform of the impulse unit is:

$$
\begin{gathered}
\Delta(w)=\int_{-\infty}^{\infty} \delta(t) e^{-j w t} d t \quad \begin{array}{c}
H(w)=\Delta(w) \cdot G(w) \\
H(w)=G(w)
\end{array} \\
\Delta(w)=1 \\
\begin{array}{c}
\text { We can say that the response of the system } \\
\text { unit is the system itself. }
\end{array} \\
G(t)=\frac{1}{2 \pi} \int_{-\infty}^{\infty} G(w) e^{j w t} d w \\
e^{j w t}=\cos (w t)+j \sin (w t) \\
g(t)=\frac{1}{2 \pi} \int_{-\infty}^{\infty}[(G \cos \theta \cos (w t)+j G \cos \theta \sin (w t)+j G \sin \theta \cos (w t)-G \sin \theta \sin (w t)] d w \\
g(t)=\frac{1}{2 \pi} \int_{-\infty}^{\infty}[(G \cos \theta \cos (w t)-G \sin \theta \sin (w t)+j G \cos \theta \sin (w t)+j G \sin \theta \cos (w t)] d w
\end{gathered}
$$

But, $\mathrm{G} \cos \theta$ is an even function and $\sin (w t)$ is an odd function so, the product is an odd function and the integral is null $\mathrm{G} \sin \theta$ is an odd function and $\cos (w \mathrm{t})$ is an even function; so the product is an odd function.

Then the integral is null.

$\mathrm{G} \cos \Theta \cos (\mathrm{wt})$ is an even function as the same way $\mathrm{G}$ $\sin \theta \sin (w t)$.

So the equation is reduced to:

$$
g(t)=\frac{1}{\pi} \int_{0}^{\infty}[(G \cos \theta \cos (w t)-G \sin \theta \sin (w t)] d w
$$

What is logical, because $\mathrm{g}(\mathrm{t})$ is a function in the domain of Real numbers. There is another simplification, from the Theory of Complex Numbers:

$$
g(t)=\frac{1}{2 \pi j} \int_{-j \infty}^{j \infty}\left[G(s) e^{s t}\right] d s
$$

To calculate this integral, with its distribution on the imaginary axis to close path, using a half circle with an infinite radius in the right side of the complex plan; the value of the integral is zero to all singularities that are to the left of imaginary axis. Then to (2), we have: where $\Delta(\mathrm{w})$ is the impulse unit response in the frequency domain.

This way in the frequency domain we have:

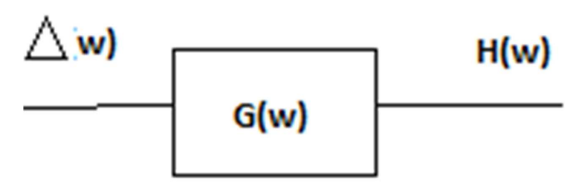

Figure 2. Impulse response frequency domain.

We can say that the response of the system to the impulse

$$
\int_{0}^{\infty}[G \cos \theta \cos (w t)] d w=\int_{0}^{\infty}[G \operatorname{sen} \theta \sin (w t)] d w ;
$$

However by inspection, we verify that the left side of (3) is an even function, although the right side is an odd function, so we have for all $t>0$ :

$$
\int_{0}^{\infty}[G \cos \theta \cos (w t)] d w=-\int_{0}^{\infty}[G \operatorname{sen} \theta \operatorname{sen}(w t)] d w
$$

So we can rewrite (2),

$$
g(t)=\frac{2}{\pi} \int_{0}^{\infty}[(G \cos \theta \cos (w t)] d w
$$

This integral exists, since:

$$
\lim _{w \rightarrow \infty} G(w)=0
$$

\subsection{Step Unit Response [1-2]}

Until now it was Floyd's Method. From now one we introduce some modifications to calculate the Step Unit Response. We know that the step unit function $r(t)$ is the integral of the impulse unit function, $h(t)$. So the step unit 
response will be the integral of the impulse unit response:

$$
\begin{gathered}
r(t)=\int_{0}^{t} g(t) d t \\
r(t)=\frac{2}{\pi} \int_{0}^{t} \int_{0}^{\infty}[G \cos \theta \cos (w \lambda)] d w d \lambda \\
r(t)=\frac{2}{\pi} \int_{0}^{\infty} \int_{0}^{t}[G \cos \theta \cos (w \lambda)] d \lambda d w \\
r(t)=\frac{2}{\pi} \int_{0}^{\infty}\left[G \cos \theta \frac{\sin (w \lambda)}{w} \mid \begin{array}{l}
t \\
0
\end{array}\right] d w \\
r(t)=\frac{2}{\pi} \int_{0}^{\infty} G \cos \theta \frac{\sin (w t)}{w} d w
\end{gathered}
$$

$$
\begin{gathered}
r(t)=\frac{2}{\pi} \sum_{w=0}^{B} \int_{w_{i}}^{w_{j}} \frac{\left(a_{i} w+b_{i}\right) \sin (w t)}{w} d w \\
r(t)=\frac{2}{\pi} \sum_{w=0}^{B}\left[a_{i} \int_{w_{i}}^{w_{j}} \sin (w t) d w+b_{i} \int_{w_{i}}^{w_{j}} \frac{\sin (w t)}{w} d w\right] \\
r(t)=-\left.\frac{2}{\pi} \sum_{w=0}^{B} \frac{a_{i} \cos (w t)}{t}\right|_{w_{i}} ^{w_{j}}+\frac{2}{\pi} \sum_{w=0}^{B} b_{i} \int_{w_{i}}^{w_{j}} \frac{\sin (w t)}{w} d w
\end{gathered}
$$

Calculating this integral,

$$
\begin{gathered}
\int_{w_{i}}^{w_{j}} \frac{\sin (w t)}{w} d w ; \text { doing } w t=x \text { and } d w=\frac{d x}{t} \\
\int_{w_{i}}^{w_{j}} \frac{\sin (w t)}{w} d w=\int_{w_{i} t}^{w_{j} t} \frac{\sin (x)}{\frac{x}{t}} \frac{d x}{t}=\int_{w_{i} t}^{w_{j} t} \frac{\sin (x)}{x} d x
\end{gathered}
$$

Imposing that $G \cos \theta$ were linearized by sectors in the frequency band $\mathrm{B}$, we have that equation (5) becomes the following equation:

$$
r(t)=\frac{2}{\pi} \sum_{w=0}^{B} \int_{w_{i}}^{w_{j}} \frac{G \cos \theta \sin (w t)}{w} d w
$$

Then

$$
\int_{w_{i} t}^{w_{j} t} \frac{\sin (x)}{x} d x=\int_{0}^{w_{j} t} \frac{\sin (x)}{x} d x-\int_{0}^{w_{i} t} \frac{\sin (x)}{x} d x
$$

We can consider $G \cos \theta \sin \quad$ the linear form $a w+b$. Then:

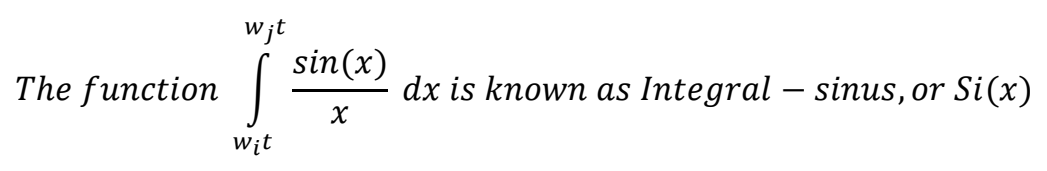

Then

$$
r(t)=-\frac{2}{\pi} \sum_{w=0}^{B}\left\{\frac{a_{i}\left[\cos \left(w_{i} t-\cos (w j t)\right)\right]}{t}\right\}+\frac{2}{\pi} \sum_{w=0}^{B}\left\{b_{i}\left[\operatorname{Si}\left(w_{j} t\right)-\operatorname{Si}\left(w_{i} t\right)\right]\right\}
$$

\subsection{Determination of the Angular and Linear Coefficients of the Linearization}

In figure 3 , we have:

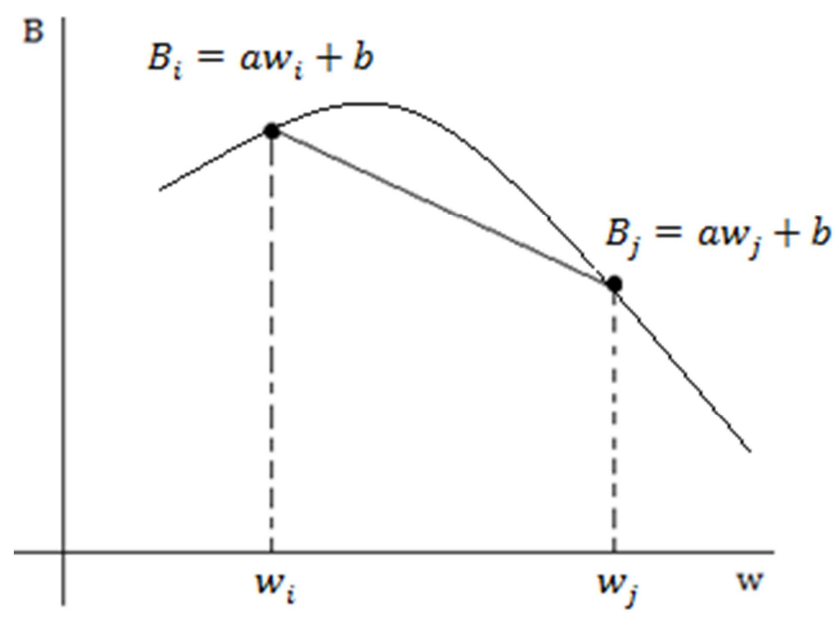

Figure 3. Gcos $\Theta$ graphic.

$$
\begin{aligned}
& B_{i}=G_{i} \cos \left(\theta_{i}\right)=a w_{i}+b \\
& B_{j}=G_{j} \cos \left(\theta_{j}\right)=a w_{j}+b
\end{aligned}
$$

If we do (7) - (8), we have:

$$
\begin{gathered}
B_{i}-B_{j}=a\left(w_{i}-w_{j}\right) \\
a=\frac{B_{i}-B_{j}}{w_{i}-w_{j}}
\end{gathered}
$$

Putting (9) em (7), we determine the coefficients

$$
\begin{gathered}
B_{i}=\left(\frac{B_{i}-B_{j}}{w_{i}-w_{j}}\right) w_{i}+b \\
B_{i} w_{i}-B_{i} w_{j}=B_{i} w_{i}-B_{j} w_{i}+b\left(w_{i}-w_{j}\right) \\
\text { So, } b=\frac{B_{j} w_{i}-B_{i} w_{j}}{w_{i}-w_{j}} .
\end{gathered}
$$

Then the equation of the straight right is: 


$$
\begin{gathered}
B=\left(\frac{B_{i}-B_{j}}{w_{i}-w_{j}}\right) w+\left(\frac{B_{j} w_{i}-B_{i} w_{j}}{w_{i}-w_{j}}\right) \quad(10) \quad \text { Putting (7) and (8) in (10) we have the final equation: } \\
r(t)=\frac{2}{\pi} \sum_{w=0}^{B}\left[\left(\frac{G_{j} \cos \left(\theta_{j}\right)-G_{i} \cos \left(\theta_{i}\right)}{w_{i}-w_{j}}\right) \cdot\left(\frac{\cos \left(w_{j} t\right)-\cos \left(w_{i} t\right)}{t}\right)+\left(\frac{w_{i} G_{j} \cos \left(\theta_{j}\right)-w_{j} G_{i} \cos \left(\theta_{i}\right)}{w_{i}-w_{j}}\right) \cdot\left(\operatorname{Si}\left(w_{j} t\right)-\operatorname{Si}\left(w_{i} t\right)\right)\right]
\end{gathered}
$$

\subsection{Realization [6, 9, 13-17]}

We have the second order system whose expression in the frequency domain (Laplace Transform) is:

$$
G(s)=\frac{w_{n}^{2}}{s^{2}+2 \zeta w_{n} s+w_{n}^{2}}
$$

We make $\zeta=0,2$ and $\mathrm{w}_{\mathrm{n}}=1 \mathrm{rad} / \mathrm{s}$. Making $\mathrm{s}=\mathrm{jw}$.

It follows the graphic of Gain and Phase of the above system given using Matlab:

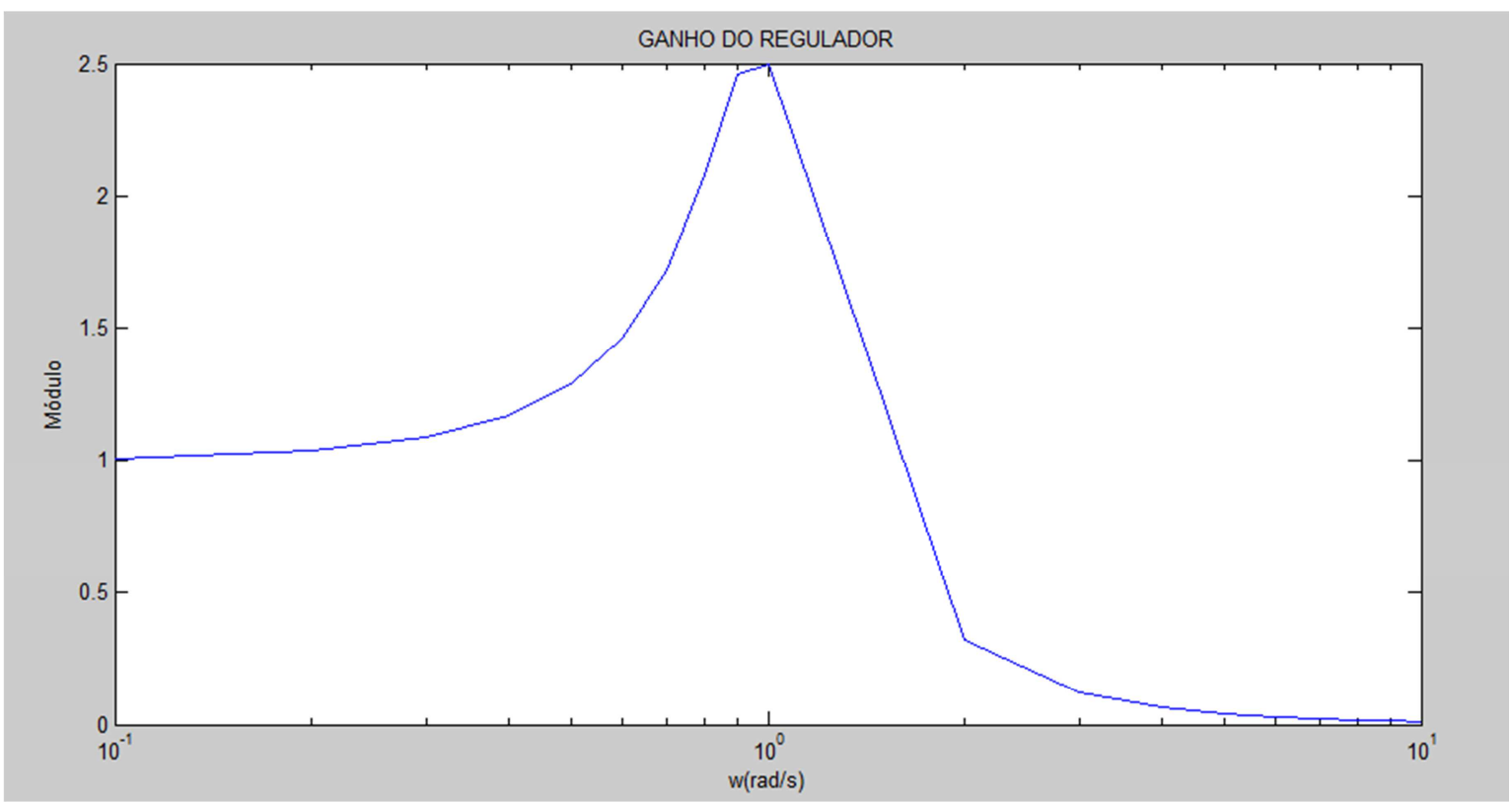

Figure 4. Gain of the second order system.

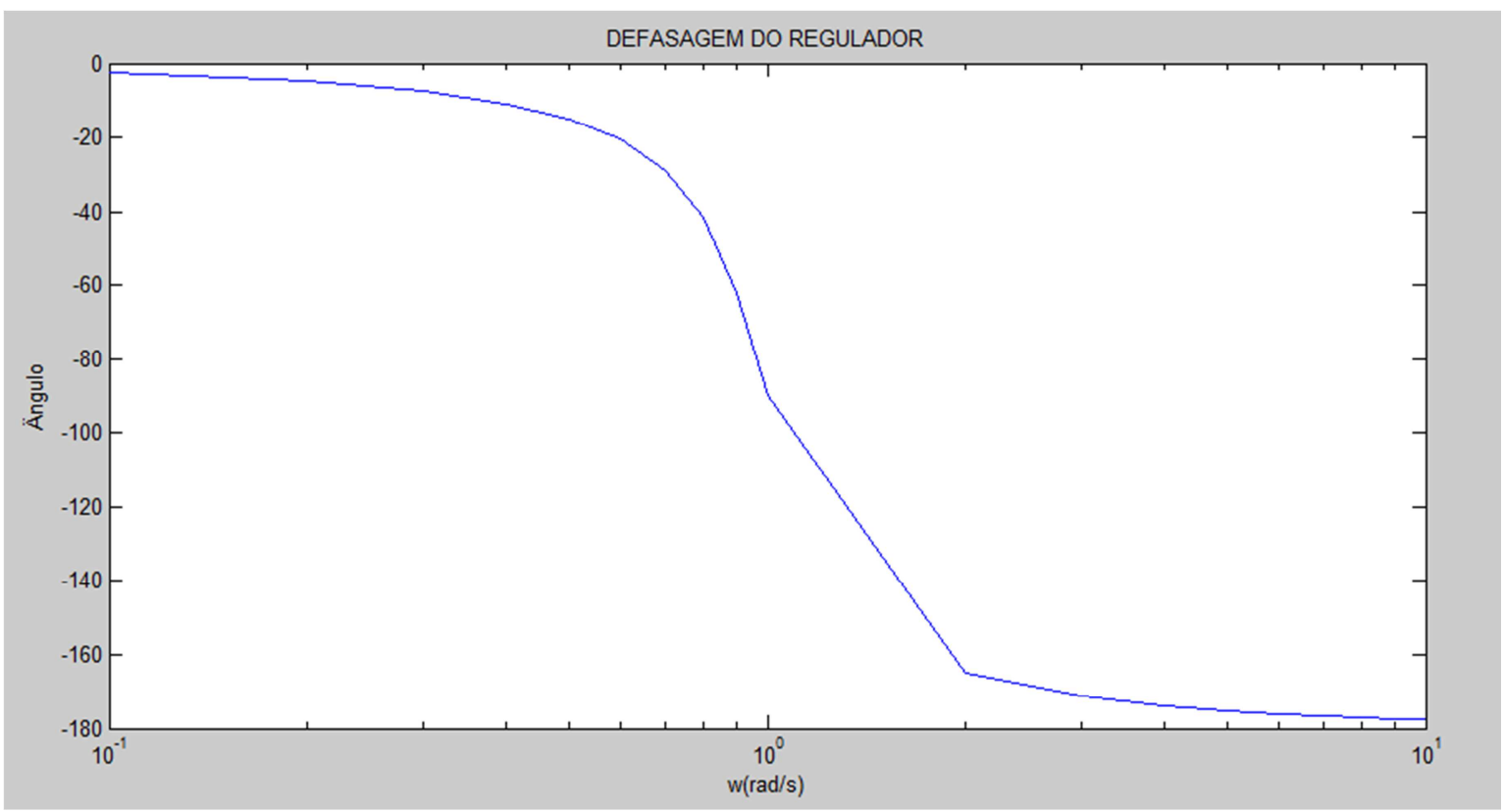

Figure 5. Phase of the second order system. 
In the case we have the frequency, $\mathrm{f}$ in $\operatorname{Hertz}(\mathrm{Hz})$, we should convert:

$$
w=2 \pi f(\mathrm{rad} / \mathrm{s})
$$

In the case we have the gain $(\mathrm{g})$ in Decibell $(\mathrm{dB})$, we should convert, $G=10^{\frac{g}{20}}$.

Using Matlab code we calculate the step unit response $r(t)$ for each $t$, varying from 1 to 20 by Floyd's Modified Method employing (11) (the cross).

$\%$ Escopo

clear all; clc; close all;

$\%$

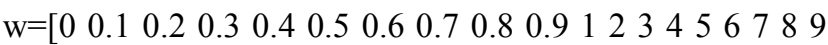
10];

$[\mathrm{G}, \mathrm{mG}, \mathrm{aG}]=$ respfreq $(\mathrm{w})$;

$\mathrm{t}=1: 20$;

$[\operatorname{lims}]=$ geramatriz $(\mathrm{w}(\mathrm{t}))$;

for $\mathrm{m}=1: 20$

for $\mathrm{k}=1: 20$ end

senointegral $(\mathrm{m}, \mathrm{k})=$ quad('senodivx', $0, \operatorname{lims}(\mathrm{m}, \mathrm{k}))$;

end

for $\mathrm{k}=1: 20$

end

$$
\text { senointegral }(k, 1)=0 \text {; }
$$

for $\mathrm{t}=1: 20$

respostafinal $(\mathrm{t})=0$;

for $\mathrm{k}=1: 19$

degrau=floyd $(\mathrm{t}, \mathrm{w}, \mathrm{k}, \mathrm{senointegral}, \mathrm{mG}, \mathrm{aG})$; end

respostafinal $(t)=$ respostafinal $(t)+$ degrau;

end

$\mathrm{t}=1: 20$;

plot( $(\mathrm{t}$, respostafinal $(\mathrm{t}))$;

title('RESPOSTA AO DEGRAU UNITARIO NO

DOMINIO DO TEMPO');

xlabel('tempo(s)'); ylabel('r(t)') function $[\mathrm{G}, \mathrm{mG}, \mathrm{aG}]=$ respfreq $(\mathrm{w})$

$\mathrm{G}=1 . /\left(-\mathrm{w} .{ }^{\wedge} 2+1+\mathrm{j} .{ }^{*} 0.4 .{ }^{*} \mathrm{w}\right)$;

$\mathrm{mG}=\mathrm{abs}(\mathrm{G})$;

$\mathrm{aG}=\operatorname{angle}(\mathrm{G})$;

function $[\operatorname{lims}]=$ geramatriz $(\mathrm{w})$

for $\mathrm{t}=1: 20$

$$
\begin{aligned}
& \text { for } \mathrm{m}=1: 20 ; \\
& \quad \operatorname{lims}(\mathrm{t}, \mathrm{m})=\mathrm{t} .{ }^{*} \mathrm{w}(\mathrm{m})
\end{aligned}
$$

end

function $[$ resposta $]=$ floyd $(\mathrm{t}, \mathrm{w}, \mathrm{k}$, senointegral $, \mathrm{mG}, \mathrm{aG})$

auxa $=\left(\left(\mathrm{mG}(\mathrm{k}) \cdot{ }^{*} \cos (\mathrm{aG}(\mathrm{k}))-\mathrm{mG}(\mathrm{k}+1) \cdot{ }^{*} \cos (\mathrm{aG}(\mathrm{k}+1))\right) \cdot /(\mathrm{w}(\right.$

$\mathrm{k})-\mathrm{w}(\mathrm{k}+1))) \cdot *\left(\cos \left(\mathrm{w}(\mathrm{k}) \cdot{ }^{*} \mathrm{t}\right)-\cos \left(\left(\mathrm{w}(\mathrm{k}+1) \cdot{ }^{*} \mathrm{t}\right)\right)\right) \cdot / \mathrm{t}$; $\%$

$\mathrm{auxb}=\left(\mathrm{w}(\mathrm{k}) \cdot{ }^{*} \mathrm{mG}(\mathrm{k}+1) \cdot{ }^{*} \cos (\mathrm{aG}(\mathrm{k}+1))-\mathrm{w}(\mathrm{k}+1) \cdot{ }^{*} \mathrm{mG}(\mathrm{k}) \cdot{ }^{*} \mathrm{c}\right.$ os $(\mathrm{aG}(\mathrm{k}))) \cdot /(\mathrm{w}(\mathrm{k})-\mathrm{w}(\mathrm{k}+1)) \cdot *($ senointegral $(\mathrm{t}, \mathrm{k}+1)$-senointegral $(\mathrm{t}, \mathrm{k}))$;

$\%$

resposta $=($ auxa + auxb $) . * 2 . / p i ;$

function $[\mathrm{razao}]=\operatorname{senodivx}(\mathrm{x})$

razao $=(\sin (x)) \cdot / x$

Note: is of fundamental importance to start with gain and phase with $\mathrm{w}=0$, otherwise we find incoherent results.

The analytic step unit response of the system (12) is:

$$
r(t)=1-\frac{1}{\beta} e^{-\zeta w_{n} t} \sin \left(w_{n} \beta t+\theta\right)
$$

where,

$$
\beta=\sqrt{1-\zeta^{2}} \text { and } \theta=\arctan \frac{\beta}{\zeta}
$$

And we compare the computational result of equation (11) with (13) (the continuous line) and plot them in the figure 6 bellow.

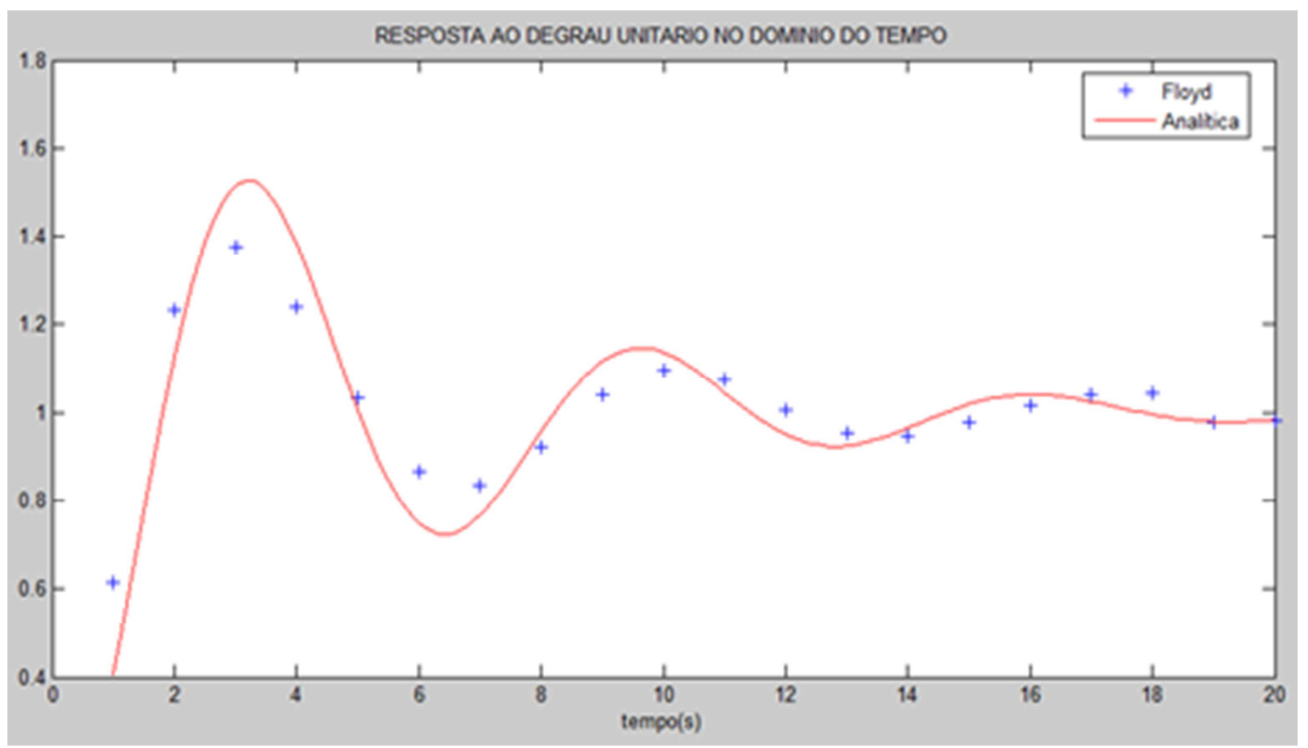

Figure 6. Step Response. 


\subsection{Error Analysis}

The table 1 bellow shows the relative error between the analytic response and linearization of Floyd's Modified Method.

Table 1. Relative Error-\%.

\begin{tabular}{ll}
\hline Time (s) & error $(\%)$ \\
\hline 1 & 51,7522 \\
2 & 9,3152 \\
3 & $-9,2008$ \\
4 & $-10,5220$ \\
5 & 2,7339 \\
6 & 15,9879 \\
7 & 8,9201 \\
8 & $-3,4275$ \\
9 & $-6,9685$ \\
10 & $-3,6313$ \\
11 & 2,7998 \\
12 & 5,8672 \\
13 & 3,0082 \\
14 & $-1,9419$ \\
15 & $-3,9843$ \\
16 & $-2,2213$ \\
17 & 1,4295 \\
18 & 4,7976 \\
19 & $-0,1563$ \\
20 & $-0,3408$ \\
\hline
\end{tabular}

\section{Conclusion}

With the results attained, we observe that with the linearization of the Floyd's Modified Method we have some little retard of the time, and inferior values, since we do not consider the whole curve of frequency response and we linearize i too. But to final values the Floyd's Method is good.

\section{References}

[1] GORDON, J. M. Basic Automatic Control Theory. First Edition, June 1957. D. Van Nostrand Company, INC. Princeton, New Jersey.
[2] CLOSE, M. C. Circuitos Lineares - vol. 2 Editora da Universidade de São Paulo. Livros Tecnicos e Cientificos. Editora AS. Rio de Janeiro, RJ. 1975.

[3] DORF, R, C. Sistemas Automaticos de Control: Teoria y Prática. Fundo Educativo Interamericano, AS. 1977.

[4] Ogata, Katsuhiko Engenharia de Controle Moderno, Prentice Hall do Brasil.

[5] Simon Haykin e Barry Van Veen, Sinais e Sistemas, Bookmaqn.

[6] Transformadas de Laplace, Coleção Schaum, Editora Mac Graw Hill do Brasil, LTDA.

[7] Digital Control of Dynamic Systems, Gene F. Franklin, J. David Powell, Michael L. Workman, Addison Wesley Publishing Company.

[8] John J D’Azzo, Constantine H. Houpis, Análise e Projeto de Sistemas de Controle Lineres, Editora Guanabara Dois.

[9] Élia Yathie Matsumoto, Matlab6.5 Fundamentos de Programação, Editora Érica.

[10] Erwin Kreyszig. Matemática Superior vols. 1, 2, 3 e 4, Livros Técnicos e Científicos Editora S. A.

[11] Ruel V. Churchill, Variáveis Complexas e Suas Aplicações. Mc Graw-Hill.

[12] Wilfred Kaplan, Cálculo Avançado vols, 1 e 2, Editora Edgard Blucher, LTDA.

[13] Joseph A. Edminister, Circuitos Elétricos, Coleção Schaum. McGraw-Hill.

[14] Joseph J. Distefano e Allen R. Stubberud - Ivan J. Williams, Sistemas de Retroação e Controle, Coleção Schaum, Editora Mc Graw Hill do Brasil LTDA.

[15] George J. Thaler, Elementos de la Teoria de Servosistemas, Biblioteca Universal de Obras Tecnicas, Editorial Labor S. A.

[16] Paulo Alvaro Maya e Fabrizio Leonardi, Controle essencial, Pearson.

[17] John G. Truxal, Introductoy Systrem Engineerig, McGRAWLL-HILL KOGAKUSHA. LTD. 